\title{
A study on Electrosynthesis of 2,5-dichlorophenol Using Titanium Anode Coated with Metallic Oxide
}

Xiangyu Ma ${ }^{1,2}$, Xuguo $\mathrm{Tu}^{1,2}$, Ruinan $\mathrm{He}^{1,2}$,Yanjun $\mathrm{Wu}^{1}$, Beibei Zhang ${ }^{1}$, Yunshan Bai ${ }^{1}$, Jianping Zeng ${ }^{1}$, Shouyan Shao ${ }^{2}$, Guisheng Zhu', Song Chen ${ }^{1,2^{*}}$

${ }^{1}$ School of Chemistry and Chemical Engineering, Yancheng Institute of Technology, Yancheng 224051, P. R. China

${ }^{2}$ College of chemistry and chemical engineering, Jiangsu University, Zhenjiang, Jiangsu 212013, P.R.

China

*E-mail: $15005101586 @ 163 . c o m$

doi: $10.20964 / 2018.01 .10$

Received: 25 September 2017 / Accepted: 24 October 2017 / Online Published: 1 December 2017

A conventional thermal decomposition method was used to prepare Sn-Ir electrodes modified with Sb-, Co-, and Ce-based oxides, which were applied to synthesize 2,5-dichlorophenol by the electrooxidation of 1,4-dichlorobenzene. The morphology of the electrodes was investigated by scanning electron microscopy (SEM) and X-ray diffraction (XRD). Cyclic voltammetry (CV) and linear sweep voltammetry (LSV) tests were employed to analyse the electrolysis experiment and electrocatalytic activity of the electrodes. The results showed that Sn-Ir electrodes doped with designated amounts of $\mathrm{Sb}$, Co or Ce could compact the coating, and improve the stability of the electrode. Typically, Sn-Ir doped with $1 \%$ Ce had a good response in the LSV measurement, which yielded a 2,5-dichlorophenol concentration of $45 \%$ with a selectivity of $85 \%$. The conversion rate of 1,4-dichlorobenzene was $53 \%$, which indicated that the Sn-Ir-Ce electrode had a better catalytic activity.

Keywords: 2,5-dichlorophenol; electrosynthesis; $\mathrm{Sn}$; Ir; Sb; Ce; Co

\section{FULL TEXT}

(C) 2018 The Authors. Published by ESG (www.electrochemsci.org). This article is an open access article distributed under the terms and conditions of the Creative Commons Attribution license (http://creativecommons.org/licenses/by/4.0/). 